\title{
Effect of different particle size reduction techniques on the nefopam and aciclovir dispersity
}

\author{
N.A.Pinchukova ${ }^{1}$, N.A.Lyapunov ${ }^{1}$, E.P.Bezuglaya ${ }^{1}$, \\ A.Yu.Voloshko ${ }^{1}$, A.N.Lyapunov ${ }^{1}$,M.A.Merko ${ }^{2}$, V.A.Chebanov ${ }^{1,2}$ \\ ${ }^{1}$ SSI "Institute for Single Crystals", National Academy of Sciences of \\ Ukraine, 60 Lenin Ave., 61001 Kharkiv, Ukraine \\ ${ }^{2}$ V.Karazin Kharkiv National University, \\ 4 Svobody Sq., 61022 Kharkiv, Ukraine
}

\section{Received August 04, 2015}

\begin{abstract}
Presents the results of application of different particle size reduction approaches to the drug substances - aciclovir and nefopam, namely, wet milling, ultrasonic (US) dispergation, US crystallization and US antisolvent precipitation. All ultrasonic experiments were performed at two operation frequencies -22 and $44 \mathrm{kHz}$. It was shown that the crucial parameters in US processes were US output power and sonication time, while the US frequency had a minor effect within the studied power range. US antisolvent precipitation showed the best results among the applied techniques yielding micron-sized particles of aciclovir, which makes this method a very promising technique in nanocrystallization area. The obtained study results provide an opportunity to choose the optimal particle reduction technique depending on the necessary particle size of drug substance suitable for a particular dosage form.

Keywords:particle size reduction, ultrasound dispergation, wet milling, crystallization, drug substance.
\end{abstract}

Приведены результаты исследования эффективности применения различных методов механического измельчения в жидких средах, ультразвукового диспергирования, ультразвуковой изогидрической кристаллизации и ультразвуковой кристаллизации с заменой растворителя - для получения мелкодисперсных лекарственных субстанций ацикловира и нефопама. Все ультразвуковые эксперименты осуществлялись с применением двух частот - 22 и 44 кГц. Показано, что ключевыми параметрами в ультразвуковых экспериментах, влияющими на конечный результат, являются мощность ультразвука и время облучения, в то время как частота не оказывает существенного влияния в пределах изученного диапазона. Наилучшие результаты показали эксперименты по ультразвуковой кристаллизации с заменой растворителя, в результате которых были получены частички ацикловира микронного размера, что делает данный метод преспективным для применения в области нанокристаллизации. Полученные результаты дают возможность выбирать оптимальный метод получения мелкодисперсных субстанций в зависимости от требуемого размера частиц для приготовления конкретной лекарственной формы.

Вплив різних методів зменшення розміру часток на гранулометричний склад нефопаму і ацикловіру. Н.О.Пінчукова, М.О.Ляпунов, О.П.Безугла, О.Ю.Волошко, О.М.Ляпунов, М.О.Мерко, В.А.Чебанов.

Наведено результати дослідження ефективності застосування різних методів - механічного подрібнення у рідкому середовищі, ультразвукового диспергування, ультразвукової ізогідричної кристалізації та кристалізації із заміною розчинника - для отримання дрібнодисперсних лікарських субстанцій ацикловіру та нефопаму. Всі ульт- 
развукові експерименти здійснювалися на двох частотах - 22 і 44 кГц. Показано, що ключовими параметрами в ультразвукових експериментах, що впливають на кінцевий результат, є потужність ультразвуку та час опромінювання, в той час як частота не впливає значною мірою у межах дослідженого діапазону. Серед усіх методів найкращі результати показали експерименти з ультразвукової кристалізації ацикловіру із заміною розчинника, в яких було отримано частки мікронного розміру, що робить цей метод перспективним з точки зору застосування у сфері нанокристалізації. Отримані результати дають можливість обирати оптимальний метод одержання дрібнодисперсних субстанцій в залежності від розміру часток, потрібного для виготовлення конкретної лікарської форми.

\section{Introduction}

Particle properties of drug substances, in particular, mean particle size and particle size distribution (PSD), are very important for medicinal products due to a great effect on their quality, effectiveness and safety. Due to much larger surface area of micronized substances as compared to conventional powders the saturation solubility is increased (Ostwald-Freundlich equation [1]) and dissolution kinetics is accelerated (Noyes-Whitney equation [2]) [3]. Enhanced solubility allows faster drug release, and, thus, higher drug concentration is reached at the absorption site. Since about 40 per sent of the marketed drugs have low water solubility [4] this effect is especially important for such drugs.

Successful particle size reduction is determined by physicochemical properties of drug substances and in a great measure by the applied technology. Nowadays a variety of techniques has been developed to achieve micro- and nano-sized powders [5-11], among which one of the most conventional ones is wet (media) milling. However, this technique have limitations in its particle size reduction performance, such as long production times and the risk of overheating leading to re-crystallization of the drug substance, as well as the risk of lower stability due to the formation of undesirable impurities [3, 12, 13]. To achieve homogeneous PSD, the micronization process should be strictly controlled. In this respect ultrasound (US) appears to be a good alternative to the conventional "mechanical" milling, being distinguished by higher efficiency and process controllability.

The effects produced by US are attributed to the cavitation phenomenon [14], allowing its various applications. The benefits provided by US are well known and are widely exploited, e.g. for powders dispersion, surface cleaning, as well as in sonochemistry and sonocrystallization. It has been shown that crystallization induced by US results in the formation of finer particles along with higher reproducibility of the results due to reduction of the induction time, narrowing metastable zone width (MZW) and lowering supersaturation level [14]. The mechanisms leading to the remarkable results obtained with US, are actively discussed in literature. For example, the US nucleation model was proposed in accordance with the heterogeneous nucleation mechanism, suggesting that the crystals nuclei were formed on the foreign surfaces of the cavitation bubbles, thus resulting in the reduction of the nucleation work [15]. John Dodds et al. offered the hypothesis based on the segregation in a liquid mixture by pressure gradients induced by cavitation bubbles [16]. The authors suggested that cavitation bubbles produced the drastic segregation effect in the surrounding liquid and, thus, promoted nucleation by acting as a cluster attachment reactor. At the same time, the enhanced diffusion due to ultrasonic waves was claimed to have a minor effect on the nucleation mechanism. In any way, the use of US allows better control over crystallization due to regulation of nucleation-crystal growth balance [17].

Generally, the typical equipment used in US crystallization is operated at frequencies ranging from 20 to $300 \mathrm{kHz}$. However, Jeroen Jordens et al. reported better results for lower frequencies, viz. $41 \mathrm{kHz}$, at which higher reduction degrees of MZW and limited degradation of the processed substance were observed as compared to higher frequencies [18].

In this work the influence of different techniques of drug substances micronization, viz. wet milling, US dispergation and US crystallization, on the mean particle size, shape and PSD of nefopam and aciclovir, were studied.

Nefopam ((RS)-5-methyl-1-phenyl-1,3,4,6tetrahydro-2,5-benzoxazocine) and aciclovir (2-amino-9-[(2-hydroxyethoxy)methyl]-1,9-d ihydro-6H-purin-6-one) are active pharmaceutical ingredients that are included in the formulations of various approved medicinal products. Although they are representatives of different chemical classes, these substances were selected for this study because 
they both are poorly soluble in water and can be presented in the composition of finished medicinal products in the form of suspension (nefopam is used for suppositories and aciclovir - for cream). The solubility of these drug substances was examined in a variety of liquid media, and the applied methods were validated as appropriate. In US dispergation and crystallization experiments the influence of US power, frequency and sonication time on the particle characteristics was studied. The comparison of different particle size reduction techniques was made in terms of mean particle size, and PSD and proposals concerning the method choice with respect to the drug substances were given as well.

\section{Experimental}

Materials

Nefopam (Anhui Wanhe Pharmaceutical Co. Ltd, PRC) and aciclovir (Quimica Sintetica, Spain), both of pharmaceutical grade, were used in the experiments. Propylene Glycol (PG) and Polyethylene Glycol 400 (PEG 400) both of pharmaceutical grade were purchased from BASF, Germany. Ethanol, iso-propanol and all other chemicals and reagents were of analytical grade and purchased from Merck, Germany. Purified water (Ph. Eur.) was used for all experiments (if necessary).

Solubility determination

Solubility of nefopam and aciclovir in various solvents in a wide temperature ranges was studied prior to the performing milling and crystallization experiments in order to select the most suitable solvents for crystallization or as dispersion media.

Solubility of nefopam was studied in PG, water, PEG 400, and mixed solvent PG PEG $400 \quad(6: 4)$ in the temperature range from $12^{\circ} \mathrm{C}$ to $60^{\circ} \mathrm{C}$. Solubility of aciclovir was studied in PG and mixed solvent PG water (4:6). The choice of PG, PEG 400 and mixed solvents is explained by their presence in the composition of finished medicinal products - nefopam suppositories and aciclovir cream.

The concentrations of the saturated solutions were determined by method of absorption spectrophotometry (UV-vis) with help of spectrophotometer "Shimadzu UV-PharmaSpec-1700" (Japan). The following procedure was applied to both drug substances: the surplus of the substance was placed in the flask with a sealing plug, the appropriate solution was added and the mixture was kept at the set temperature with $\pm 0.1^{\circ} \mathrm{C}$ ac- curacy, with periodical stirring until the thermodynamic equilibrium was achieved. Periodically samples of the supernatant solutions were taken and their absorbance was measured. The thermodynamic equilibrium was considered to be achieved when the absorbance of two successive samples was the same. Then the mixture was allowed to stay over $3-4 \mathrm{~h}$ at the set temperature and the sample was taken again. The total saturation time made up from 10 to $100 \mathrm{~h}$ depending on the solvent used. Prior to measurements the saturated solution was diluted with $0.1 \mathrm{M}$ hydrochloric acid so that the absorbance was within 0.3 to 1.5 range.

The absorbance of nefopam and aciclovir solutions were measured at $266 \mathrm{~nm}$ and $255 \mathrm{~nm}$, respectively, the wavelengths corresponding to their maximum absorption values.

The concentration of the substance $(C, \%)$ was calculated by the formula $C=A \cdot r / E_{s p}$, where $A$ is the measured absorbance of the solution, $r$ is dilution, and $E_{s p}$ is the specific absorbance of the dissolved substance.

The methods were validated as appropriate to meet requirements, laid down in the State Ukrainian Pharmacopeia and international guides [19-21].

Particle size distribution measurements

PSD was measured by Laser Diffraction Particle Size Analyzer SALD-2201 (Shimadzu, Japan) with using iso-propanol and ethanol as liquid media for nefopam and acyclovir, respectively. The measurements were performed at least three times to ensure reproducibility of the results, which were recorded and processed using the appropriate software.

Wet milling

The suspension of the studied drug substance was prepared in the appropriate solvent in the required drug : solvent ratio. Wet milling experiments were performed using rotor-stator dispergator with high shear rates - Megatron MT 1-50 SHS F/2 (Kinematica AG, Switzerland). Various rotation speeds were applied, and the kinetics of suspension heating was monitored. Based on the results, the optimal rotation speed and process time with cooling mode were determined, allowing avoiding overheating of suspension.

Ultrasonic dispergation, crystallization and antisolvent precipitation

US dispersing was performed using US probe dispergator UZD 22/44 (Sumy-Pribor, Ukraine) operated at $22 \mathrm{kHz}$ and $44 \mathrm{kHz}$ with maximal US power output of $400 \mathrm{~W}$. To adequately compare the results of me- 
chanical milling and US dispergation the drug-liquid ratio was kept the same for both methods. The US probe with a tip diameter of $10 \mathrm{~mm}$ was immersed in the suspension by $0.5-1 \mathrm{~cm}$. Ice-water mixture was used as a cooling agent to prevent suspension overheating. The temperature was controlled by means of a temperature probe. Prior to and during US sonication the samples were taken with 5 min intervals to perform PSD measurements.

The same equipment was used as for US dispersing experiments. Water and the mixture of PG - water (9:1) were used as solvents for nefopam and aciclovir sonocrystallization, respectively. During the experiments the saturation concentrations were determined for both substances. For this purpose the weighed amount of the substance was added to the measured amount of the solvent, heated to $55^{\circ} \mathrm{C}$ and kept at this temperature for $30 \mathrm{~min}$. If any undissolved particles of the drug substance were observed, the solvent was gradually added until all the substance was dissolved. If any foreign particles were observed in the obtained solution, the latter was filtered through filter paper. Then the MZW was determined by slow cooling of the obtained solution. The MZW corresponded to the temperature drop between the saturation temperature and the one at which the first crystals of the substance appeared in the solution. Then the solutions were subjected to sonication. US generator was switched on at the temperature $5^{\circ} \mathrm{C}$ higher than the crystallization temperature. Simultaneous cooling and agitation were applied during sonication to ensure better mass and heat transfer.

US precipitation was performed by preparing the saturated solution of the substance in the appropriate solvent, and pouring the obtained solution into the antisolvent being ultrasonicated, with simultaneous cooling and agitation of the suspension.

\section{Results and discussion}

The choice of the dispersion medium for wet milling and US dispergation

In order to select the most appropriate solvent as the dispersion media for wet milling and US dispergation, the solubility of nefopam and aciclovir in different liquids was studied. The solubility diagrams of nefopam in water, PG, PEG 400 and mixed solvent PG-PEG $400(6: 4)$ are demonstrated in Fig. 1.

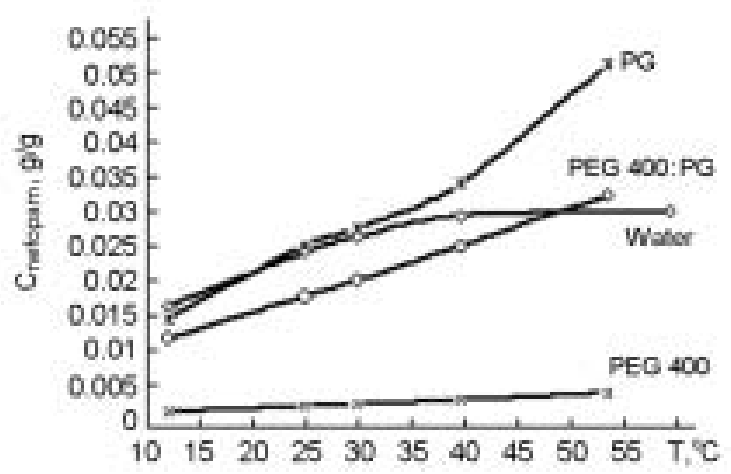

Fig. 1. Solubility of nefopam in different liquid media vs. temperature.

It was established that the most appropriate dispersion medium, in which nefopam solubility was the lowest among the examined liquids, was PEG 400 (Fig. 1). Moreover, the solubility rises insignificantly with increasing the temperature which is favorable, since the risk of the substance dissolution and re-crystallization as the result of overheating is minimal.

Similarly, the dispersion medium for aciclovir was selected among the PG and mixed solvent PG - water (4:6), which corresponds to composition of dispersion medium of cream emulsion base (w/o) (Fig. 2a).

The solubility of aciclovir in $\mathrm{PG}$ rises with temperature, though even at $70^{\circ} \mathrm{C}$ it is as low as $0.62 \%$ (Fig. 2b). The solubility in the mixed solvent $\mathrm{PG}$ - water is higher than that in PG. However, the amount of the substance that can undergo re-crystallization in this case does not exceed $0.25 \%$. Thus, the uncontrolled crystallization leading to large particles can be successfully avoided when PG is used as a suspending medium. To determine the optimal composition of the dispersion medium, the solubility of aciclovir was studied in the mixtures PG - water with PG concentrations ranging from 0 to 100 per cent. It was found that the solutions containing from 60 to 90 per cent of $\mathrm{PG}$ were unsuitable as dispersion media, since the solubility of aciclovir in them was higher than that in the dispersion medium of cream emulsion base (w/o) (Fig. 2b).

The most suitable concentration ranges were found to be below 60 per cent or close to 100 per cent. Though the solubility of aciclovir decreases with lowering PG concentration, however, the PG was finally se- 

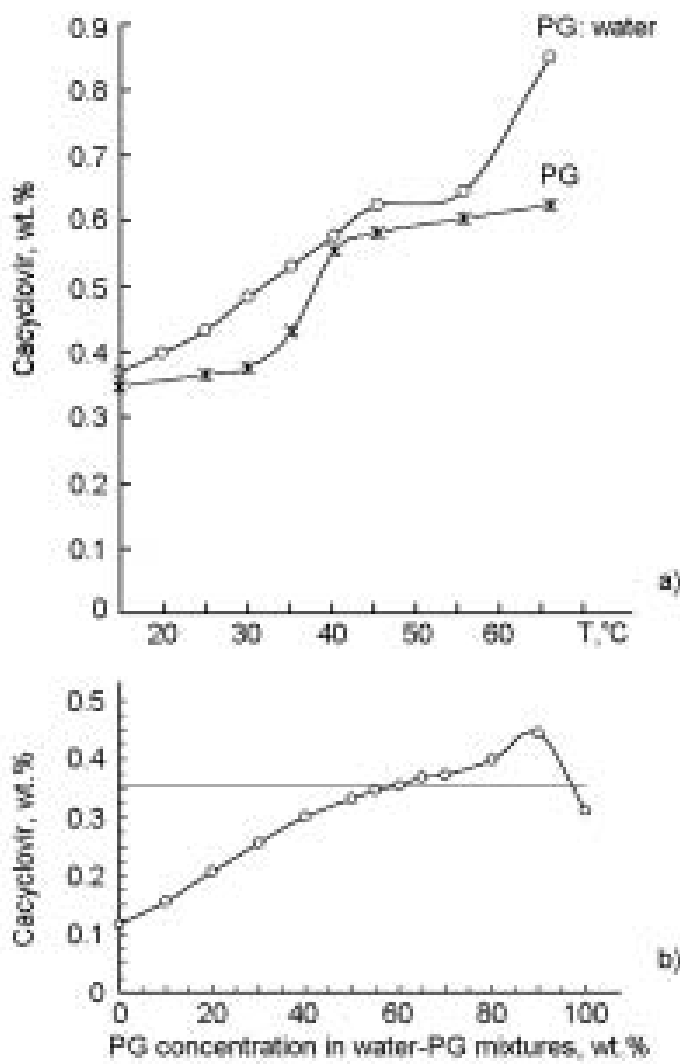

Fig. 2. Solubility of acyclovir: (a) in PG and mixed solvent PG - water vs. temperature; (b) in water - PG mixtures depending on the PG concentration. Red horizontal line indicates aciclovir solubility in the dispersion medium of cream emulsion base (w/o).

lected as the dispersion medium because of its better wetting ability.

Nefopam dispergation

The nefopam (sample of commercial drug substance obtained after conventional cooling crystallization) used in the dispergation experiments had the mean particle size of 65.3 $\mu \mathrm{m}$ and wide PSD, moreover, they have irregular crystal shape and cannot be directly used for production of suppositories. Therefore, two approaches were applied for particles micronization purposes wet milling and US dispergation.

Wet milling of nefopam was performed using dispergator Megatron with PEG-400 as dispersion medium taken in $1: 4.5$ ratio. Two rotation speeds were examined and the optimal milling mode preventing suspension heating over temperature $40^{\circ} \mathrm{C}$ was found.

Decreasing the mean particle size of nefopam from $65 \mu \mathrm{m}$ to $43 \mu \mathrm{m}$ was achieved by wet milling, however considerable amount of large particle $(>100 \mu \mathrm{m})$ were found as well, and the wide PSD was still observed.

US dispergation of nefopam was carried out with the use of US probe dispergator at two operation frequencies $-22 \mathrm{kHz}$ and $44 \mathrm{kHz}$. For comparability of the results the same drug substance/liquid ratio was applied for both mechanical and US approaches. It has been established that the influence of US frequency is minor within the studied range, whereas the US power has considerable effect on the particle sizes (Fig. 3a). Thus, the mean particle size decreases from $35 \mu \mathrm{m}$ in average to $24 \mu \mathrm{m}$ when increasing the output power from $200 \mathrm{~W}$ to $380 \mathrm{~W}$, the linear dependence of the particle size on the US power being observed. The influence of the sonication time on the particle size was also studied, and the optimal value amounting to $15 \mathrm{~min}$ for both frequencies was obtained (Fig. 3b). Further sonication was not efficient with regard to decrease of the particle size.

Evidently, further increase in US power would result in smaller particles, however, in our experiments we were limited by the maximal power capacity of the used US equipment. Thus, the best results with US dispergation lead to the particles smaller by half as compared to wet milling. Apart from smaller size, the crystals obtained after US dispergation were much more regular and uniform by the shape.

The explanation of such a difference in the results obtained with wet milling and US dispergation is, obviously, in the completely different particle size reduction mechanisms: in case of wet milling the driving force of the process is the mechanical pressure developed between the rotor and stator of the milling device, and the particle size reduction degree depends on the shear stress defined by the rotor speed, which should be very high to attain micron-sized particles. On the other hand, some part of mechanical energy dissipates in the form of heat, resulting in undesirable overheating of the suspension despite simultaneous cooling process. So, the optimal rotation speed preventing suspension overheating is not always sufficient to achieve fine particles. Moreover, the wide PSD indicates that the shear stress created in the milling device is not uniform throughout the working volume. In contrast, US dispergation proceeds due to cavitation induced by shock waves propagating in the dispersion medium. Particle size reduction degree in this case is dependent on the shock wave force. It can 

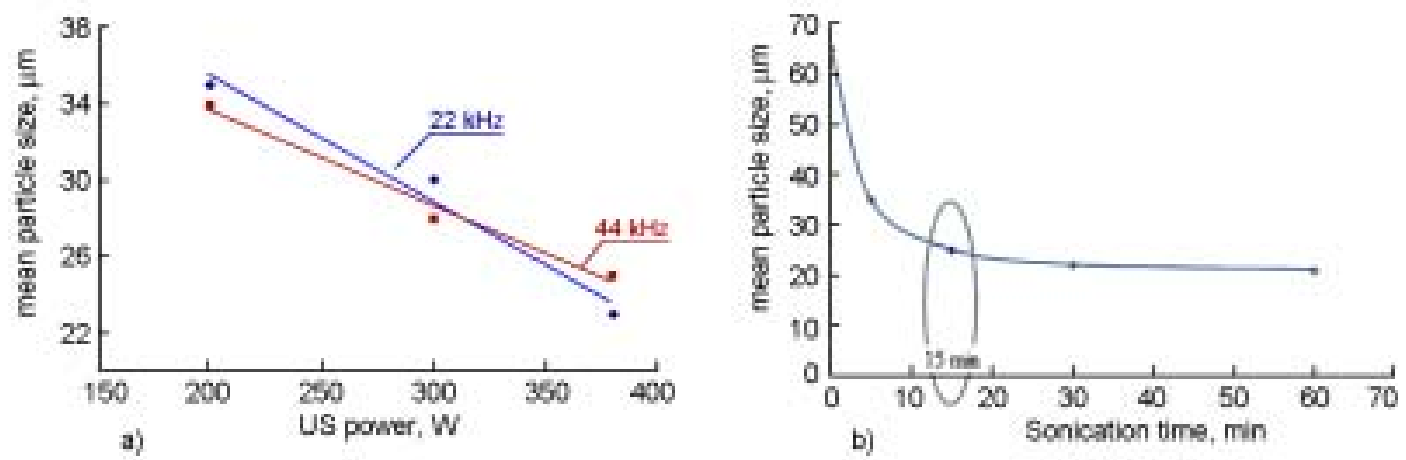

Fig. 3. The influence of US power output (a) and sonication time (b) on the mean particle size studied at $22 \mathrm{kHz}$ and $44 \mathrm{kHz}$.

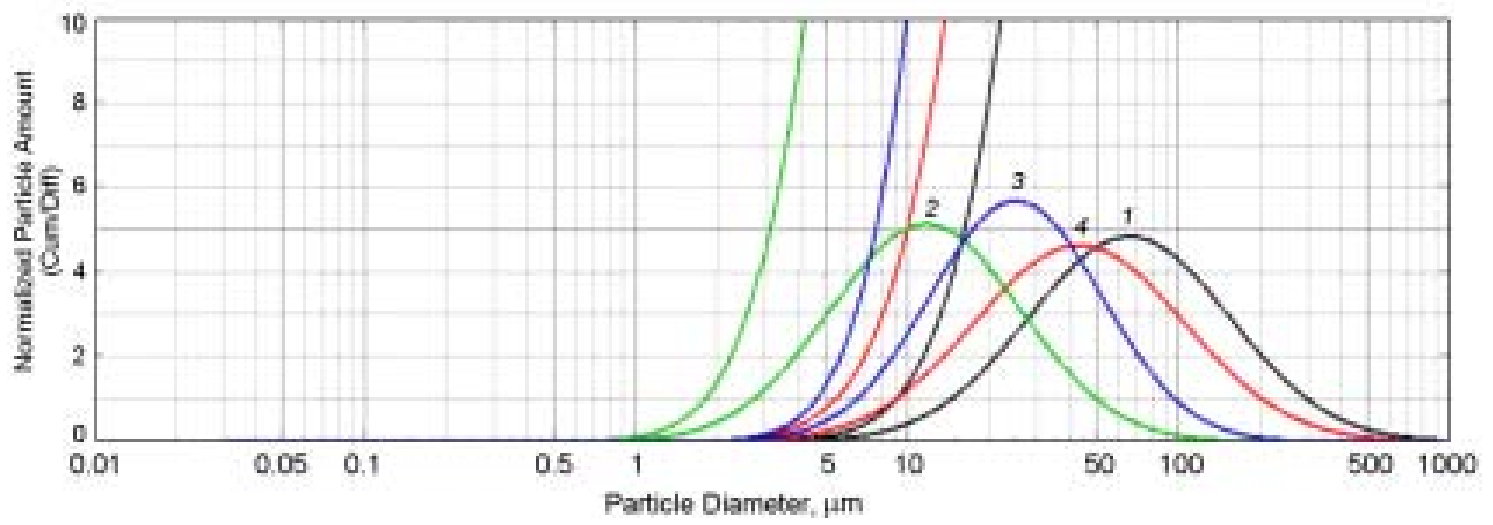

Fig. 4. PSD of the nefopam samples obtained by various techniques: 1) commercial drug substance; 2) US crystallization; 3) US dispergation; 4) wet milling.

also be assumed that the wave attenuation can be neglected in the incompressible liquid medium, therefore, the pressure produced by the shock waves may be considered uniform throughout the bulk volume. Thus, the homogeneous energy distribution throughout the bulk volume results in uniform micronization, yielding more regular particles and narrower PSD in comparison with conventional milling or crystallization, wherein such homogeneity can hardly be reached.

Based on the obtained results the following US dispergation parameters were determined: US frequency $44 \mathrm{kHz}$, power output $380 \mathrm{~W}$, and sonication time $15 \mathrm{~min}$.

Nefopam crystallization

Though US dispergation yielded much smaller particles than mechanical milling, crystallization experiments with US initiation were performed to obtain particles approaching to micron-sized powders. It is known that crystallization initiated by US results in reduction of particle size due to the decreased nucleation order, reduction of
MZW and decrease of the supersaturation limit [14]. Between PEG-400 and water, the latter was selected as a solvent, since the solubility of nefopam in water is almost 8 times higher than in PEG-400 (Fig. 1). In contrast to the ordinary cooling crystallization, which had given the average particle size ca. $65 \mu \mathrm{m}$, crystallization initiated by US led to much better results yielding particles with the average size of $11.6 \mu \mathrm{m}$, i.e. 6-fold smaller.

The summary diffraction pattern demonstrating PSD of the nefopam samples obtained by different techniques is shown in Fig. 4.

The best results were obtained with US crystallization, leaving far behind other particle size reduction methods. US dispergation rates second in this line, giving twice as large particles, though with narrow PSD, being comparable with US crystallization. Wet milling proved to be the least efficient technique among the micronization methods applied. 


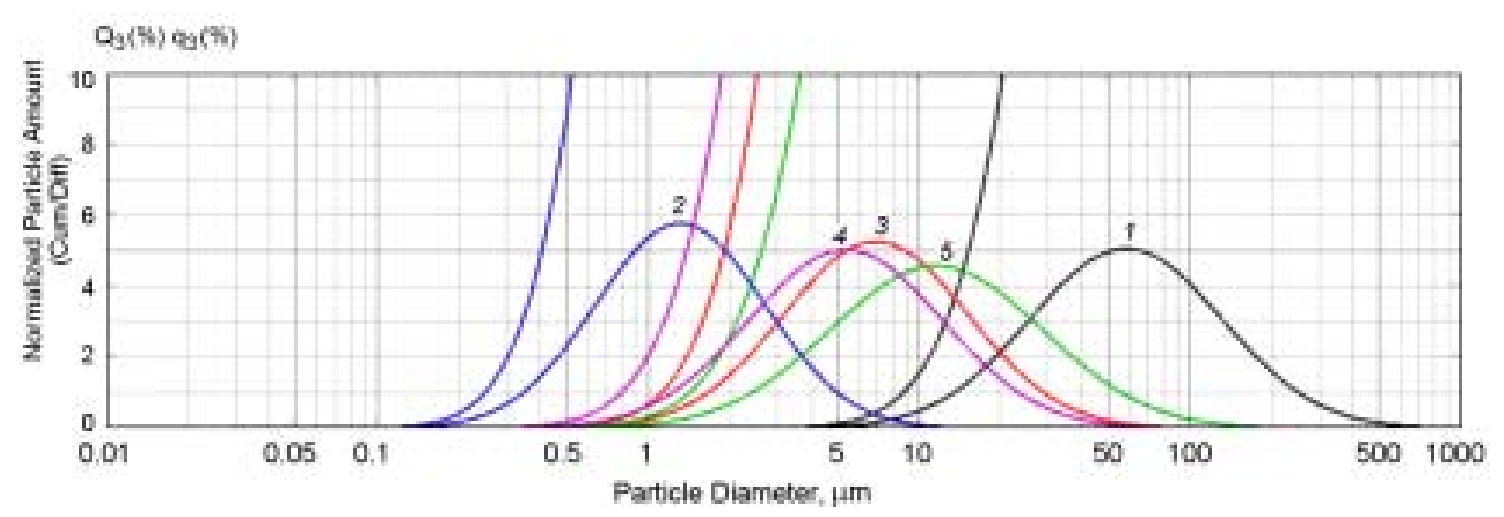

Fig. 5. PSD of the aciclovir samples obtained by various techniques: 1) ordinary crystallization; 2) US antisolvent precipitation; 3) US crystallization; 4) US dispergation; 5) wet milling.

It should be noted, however, that in spite of the outstanding results achieved with US crystallization, the ultimate choice between this method and US dispergation should be made only after comprehensive additional studies of the dosage forms. If both US crystallized and US dispersed drug substances can be used with equal profit, the choice should obviously be made in favor of US dispergation technique due its relative simplicity. On the other hand, the final decision should take into account the cost of the method and its applicability for industrial scale.

Aciclovir dispergation

Wet milling of aciclovir was performed using $P G$ as a medium for suspension taken in 1:5 weight ratio. Primary average particle size obtained after ordinary crystallization was $58 \mu \mathrm{m}$ which after the milling was reduced to $11.5 \mu \mathrm{m}$, i.e. almost by 5 times (Fig. 5 ).

US dispergation was performed with the same dispersion medium, taken in the same ratio, as in the wet milling experiments. The frequency and US power were selected based on nefopam dispergation experiments, i.e. $44 \mathrm{kHz}$ and $380 \mathrm{~W}$, respectively. The average particle size of $5.3 \mu \mathrm{m}$ was obtained after US dispergation which was twice smaller that obtained after wet milling (Fig. 5). It is noteworthy that with the same US sonication mode applied for nefopam and aciclovir dispergation, their particles sizes differ considerably (24 $\mu \mathrm{m}$ and $5.3 \mu \mathrm{m}$, respectively; Fig. 4 and 5). This difference can be explained, first of all, by the differences in crystal structure and hardness of the substances, and, secondly, to a lesser extent, by different liquid media used for dispergation of nefopam and aciclovir.

\section{Aciclovir crystallization}

Comparative crystallization experiments with aciclovir were also carried out to obtain the particles as small as possible. The mixed solvent $P G$ - water (9:1) was selected on the basis of the solubility studies (Fig. 2b). Interestingly, that the particles obtained after US dispergation were even smaller than those obtained after US crystallization (the average particle sizes being $5 \mu \mathrm{m}$ and $6.9 \mu \mathrm{m}$, respectively), which can be presumably explained by the difference in particles concentration - in US dispergation experiments the drug substance/liquid ratio was much lower than in crystallization ones (1:5 and 1:25, respectively). Thus, the US dispergation in case of aciclovir may be considered the optimal particle size reduction technique outperforming wet milling and US crystallization.

The overwhelming results were obtained with US antisolvent precipitation (Fig. 5), yielding the average particle size $1.3 \mu \mathrm{m}$. For this purpose dimethyl sulfoxide (DMSO) was taken as a solvent and water as an antisolvent. However, in spite of the dramatic effect produced by the US precipitation, it should be taken into account that some troubles could occur during isolation and purification of the precipitant. Since DMSO is a foreign substance, which is not constituent of aciclovir cream, it should be completely removed from the substance afterwards. Moreover, the isolation and drying of micron-sized powders is an individual challenging task requiring additional study. Therefore, the final decision on the preferable technique should be made after evaluation of the necessary particle size of the drug substance, suitable for the particular dosage form, as well as after conducting other required studies. 


\section{Conclusions}

The effect of various particle size reduction techniques, namely, wet milling, US dispergation, US crystallization and US antisolvent precipitation, on the mean particle size and PSD of two drug substances nefopam and aciclovir - was studied. The study results revealed the following findings:

US dispergation of drug substance suspensions gives on the average twice smaller particles and narrower PSD as compared to the wet milling technique performed with the use of a rotor-stator dispergator. US crystallization outperforms US dispergation with regard to the mean particle size and PSD due to controllable nucleation and crystal growth. US-assisted antisolvent precipitation has been shown to be the most efficient particle size reduction technique technique giving micron-sized drug particles, which is $4-5$ times less than with US crystallization. However, in this case isolation and purification of the drug substance poses a challenging task, therefore application of this technique should be justified. The performed studies provide an opportunity to choose the optimal particle size reduction technique depending on the necessary particle size of the drug substance, suitable for the particular dosage form.

\section{References}

1. A.I.Rusanov, Phase Equilibria and Surface Phenomena, Khimija, Leningrad (1967) [in Russian].

2. A.Dokoumetzidis, P.Macheras, Int.J.Pharm., 321, 1 (2006).

3. J.Zhang, L.Wu, H.-K.Chan, Adv.Drug Delivery Rev., 63, 441 (2011).

4. D.Thassu, M.Deleers, Y.Pathak, Nanoparticulate Drug Delivery Systems, Informa Healthcare USA, Inc., New York (2007).
5. C.Sun, D.Xue, Curr.Opin.Chem.Eng., 1, 108 (2012).

6. J.-U.A.H.Junghanns, R.H.Muller, Int.J. Nanomed., 3, 295 (2008).

7. H.Chen, C.Khemtong, X.Yang et al., Drug Discovery Today, 16, 354 (2011).

8. F.Kesisoglou, S.Panmai, Y.Wu, Adv. Drug Delivery Rev., 59, 631 (2007).

9. G.D.Wang, F.P.Mallet, F.Ricard, J.Y. Heng, Curr. Opin. Chem. Eng., 1, 102 (2012).

10. H.de Waard, N.Grasmeijer, W.L.J.Hinrichs et al., Eur.J.Pharm. Sci., 38, 224 (2009).

11. T.Panagiotou, S.V.Mesite, R.J.Fisher, Ind. Eng. Chem. Res., 48, 1761 (2009).

12. A.Harter, L.Schenck, I.Lee, A.Cote, Org.Process Res. Dev., 17, 1335 (2013).

13. J.Salazar, R.H.Muller, J.P.Moschwitzer, J. Pharmac., 2014, 2014 (2014), Article ID 265754.

14. M.D.Luque de Castro, F.Priego-Capote, Ultrason. Sonochem., 14, 717 (2007).

15. A.Kordylla, T.Krawczyk, F.Tumakaka, G.Schembecker, Chem.Eng.Sci., 64, 1635 (2009).

16. J.Dodds, F.Espitalier, O.Louisnard et al., Part.Part.Syst. Charact., 24, 18 (2007).

17. G.Ruecroft, D.Hipkiss, T.Ly et al., Org. Process Res. Dev., 9, 923 (2005).

18. J.Jordens, B.Gielen, L.Braeken, T.Van Gerven, Chem. Eng. Process, 84, 38 (2014).

19. State Ukrainian Pharmacopoeia, $1^{\text {st }}$ Ed., Annex 2, State Enterprise "Scientific-Advisory Pharmacopoeian Centre", Kharkiv (2008) [in Ukrainian].

20. Thechnical Guide for the Elaboration of Monographs. 4th Ed. European Pharmacopoeia, European Directorate for the Quality of Medicines (2005).

21. Validation of Analytical Procedures: Text And Methodology Q2(R1) - ICH Harmonised Tripartite Guideline, Retrieved from the Intern. Conf. on Harmonisation of Technical Requirements for Registration of Pharmaceuticals for Human Use, San Diego, USA (2014). 